\title{
Infectious diseases in the era of refugees: Hepatitis A outbreak in Lebanon
}

\author{
Abdul Rahman Bizri"1,2, Jawad Fares ${ }^{3}$, Umayya Musharrafieh ${ }^{1,4}$
}

${ }^{1}$ Department of Internal Medicine, Division of Infectious Diseases, American University of Beirut Medical Center, ${ }^{2}$ Conflict Medicine Program, Office of Strategic Health Initiatives, American University of Beirut, ${ }^{4}$ Department of Family Medicine, American University of Beirut Medical Center, Beirut, Lebanon, ${ }^{3}$ Department of Neurological Surgery, Feinberg School of Medicine, Northwestern University, Chicago, IL, USA

\begin{tabular}{|c|}
\hline Access this article online \\
\hline Website: www.avicennajmed.com \\
\hline DOI: 10.4103/ajm.AJM_130_18 \\
\hline Quick Response Code: \\
\hline
\end{tabular}

\begin{abstract}
Background: The Syrian crisis has altered the epidemiology of infectious diseases in countries hosting large numbers of refugees. Lebanon witnessed several outbreaks linked to the presence of significant numbers of Syrian refugees, namely, Hepatitis A virus (HAV). We explore the epidemiology of HAV in Lebanon and the impact of the Syrian war during the 2014 outbreak and suggest solutions to prevent and minimize the HAV spread amid the current socioeconomic conditions. Methods: We reviewed all HAV cases reported to the Epidemiologic Surveillance Unit at the Ministry of Public Health between January 2001 and December 2017. Demographics and distribution of Syrian refugees in Lebanon were linked to reports of new HAV cases. Results: A sharp rise in the number of reported HAV cases was observed in Lebanon in 2013 , concurrent with the Syrian crisis and influx of refugees. Most cases reported in 2013 and 2014 involved Syrian refugees and their relevant areas of settlement in the Beqaa and North governorates. Conclusion: The influx of refugees strained overburdened sanitary infrastructure and overstretched existing public health services in Lebanon, which led to an increase in the incidence of reported HAV cases. The Lebanese health authorities and the international community need to intensify their efforts in surveillance and prevention of communicable diseases. Providing proper sanitation and free vaccination for affected communities are effective solutions to contain the HAV outbreak. Yet, financial constraints and the need to prioritize in the health budget put HAV-immunization at a lower priority. The Lebanese scenario could be reflective to other countries hosting sizeable numbers of refugees.
\end{abstract}

Key words: Hepatitis A, Middle East, Syrian crisis, Syrian refugees, vaccination

\section{INTRODUCTION}

The Middle East continues to be at the center of turmoil, with conflicts affecting most of the region's countries. The health situation in Syria continues to worsen, with more injuries, communicable diseases, deaths, and migratory movements reported every day. In addition, neighboring and friendly countries that provide asylum and safe shelter for those who migrate are witnessing increased demographic and economic hardships. In Lebanon, for example, key drivers of growth such as construction, the service economy, and tourism have been affected because of the impact of the

Address for correspondence: Dr. Jawad Fares,

Department of Neurological Surgery, Feinberg School of

Medicine, Northwestern University, Chicago, IL 60611, USA.

E-mail: jawad.fares@northwestern.edu
Syrian war. More importantly, the ramifications of the crisis resulted in the resurgence of infectious diseases that have been dormant for years.

Lebanon, with its initially open border policy with Syria, has witnessed several outbreaks linked to the influx of large numbers of refugees into the country. The Leishmania outbreak witnessed in 2013 is an example of how wars

This is an open access journal, and articles are distributed under the terms of the Creative Commons Attribution-NonCommercial-ShareAlike 4.0 License, which allows others to remix, tweak, and build upon the work non-commercially, as long as appropriate credit is given and the new creations are licensed under the identical terms.

For reprints contact: reprints@medknow.com

Cite this article as: Bizri AR, Fares J, Musharrafieh $U$. Infectious diseases in the era of refugees: Hepatitis A outbreak in Lebanon. Avicenna J Med 2018;8:147-52. 
and military conflicts can cause and spread disease and infection. ${ }^{[1]}$

Hepatitis A virus (HAV) is a global health concern with an estimated incidence of 1.5 million symptomatic cases worldwide. It is transmitted mainly through the fecal-oral route, either by direct contact with an infected person or by the consumption of contaminated food, drinking water, and blood products. ${ }^{[2]}$ The infection confers lifelong immunity to all strains of HAV. ${ }^{[3]}$ In children, it is often asymptomatic, but in the majority of adults, the infection is clinically apparent.

HAV seroprevalence ranges between $15 \%$ and $100 \%$ in the various parts of the globe. ${ }^{[4-6]}$ Geographic area, sanitary levels, and socioeconomic conditions play a central role in its spread and prevalence in certain communities. Immunity to HAV can be determined through detecting the presence of anti-HAV Immunoglobulin G (IgG) in serum. The proportion of individuals with antibodies (IgG) to HAV has been declining in most parts of the world in recent decades. This decline has been attributed to improvement in socioeconomic status, better access to clean water, sanitation, and in some cases, to active immunization through vaccination.

In the Middle East, anti-HAV seroprevalence rates are generally high. ${ }^{[7-9]}$ Studies from many countries in the region have shown that more than $95 \%$ of adults have antibodies to HAV ${ }^{[10]}$ A 2014 report found that, in 12 out of 25 countries in the Middle East and North Africa region, the incidence of HAV declined among the younger age groups and increased among adults. ${ }^{[11]}$ In Lebanon, HAV has underwent a major epidemiologic shift where several studies showed a decrease in the seroprevalence of HAV among young children and adolescents over the past 30 years. ${ }^{[12-14]}$ This change rendered older children, adolescents, and adults more likely to acquire overt disease. ${ }^{[15]}$ Consequently, the clinical presentation of HAV infection changed, where lesser asymptomatic infections were documented and more severe symptomatic illness was encountered. Furthermore, the recent influx of Syrian refugees seeking shelter and their settlement in underserved camps might have augmented the risk of disease. ${ }^{[16]}$ Poor sanitation, unclean water supplies, and low-quality housing in these camps are all likely to contribute to the rapid spread of HAV. ${ }^{[17]}$

This study aims to: (1) explore the evolutionary patterns of HAV seroprevalence in Lebanon; (2) evaluate the effects of the Syrian crisis on HAV epidemiology in the country; and (3) offer solutions to prevent and minimize the spread of HAV.

\section{METHODS}

We explored the medical literature on HAV in Lebanon and analyzed the cases of acute HAV infection reported by the Epidemiological Surveillance Unit of the Ministry of Public Health (MOPH) in Lebanon.

HAV is a mandatory reportable infectious disease in Lebanon. Clinician observations and laboratory tests need to be reported and manually submitted to the Lebanese MOPH.

All HAV cases reported by the Epidemiologic Surveillance Unit at the Lebanese MOPH between January 2001 and December 2017 were reviewed inclusively. They were studied in terms of area of residence, age, sex, and clinical presentation.

A case was classified as "probable" if the person was presenting with acute jaundice, negative results for viral hepatitis B (negative IgM anti-HBc or HbsAg antigens), and negative or unknown results for viral hepatitis $C$ (negative anti-hepatitis $C$ virus). A case was classified as "confirmed" when a suspected or probable case was supported by laboratory testing with the presence of IgM anti-HAV antibodies or when a suspected or probable case had an epidemiological link with a laboratory-confirmed case of HAV (household or sexual contact with an infected person during the 15-50 days before the onset of symptoms).

Cases affecting Lebanese nationals were distinguished from those of Syrian refugees, and the locations of Syrian refugee tented settlements were reviewed in terms of their distribution across various Lebanese districts. The number of Syrian refugees and their distribution all over Lebanon was obtained from the United Nations High Commissioner for Refugees (UNHCR). Cases obtained were used to draw an epidemiological map eliciting the distribution of all HAV cases between 2005 and 2017 across various Lebanese governorates, along with the locations of concentrations of Syrian refugees.

\section{RESULTS}

The general trend of reported HAV cases in Lebanon since 2001 has been on the rise [Figure 1]. Between 2005 and 2017, more than 10400 cases have been reported. Yet, published studies on HAV in Lebanon have been scarce, with fewer studies exploring the disease in children and adolescents [Table 1]. ${ }^{[12-15,18]}$

The annual average number of reported HAV cases in Lebanon was around 300 cases between 2001 and 2012. In 
2014, close to 2600 cases of HAV among Lebanese nationals were reported to the MOPH, raising the possibility of a potential outbreak. This increase was mostly notable in the Beqaa and North governorates, the closest to the Syrian borders and where the highest concentrations of Syrian refugees are located. The number of Syrian refugees with symptomatic HAV and reported to the Lebanese MOPH was 220 in 2013. It increased to 859 cases in 2014. In the years that follow, the numbers of HAV cases among Syrian refugees decrease to range between 78 and 182 .

According to the Lebanese MOPH Epidemiologic Surveillance Unit website, ${ }^{[19]}$ older children and adolescents

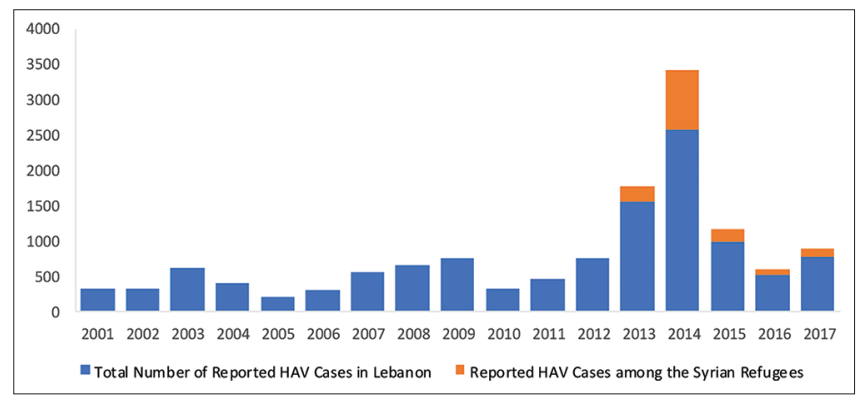

Figure 1: Reported HAV cases in Lebanon between January 2001 and December 2017 (inclusive) and the effect of the Syrian Crisis (2013-2017) on HAV incidence in the country. HAV: hepatitis A virus are at increased risk of infection; about $36 \%$ of the symptomatic reported cases are between 10 and 19 years of age. Those whose ages are above 60 years seem to be at lower risk, as older age groups have immunity to the disease; close to $53 \mathrm{HAV}$ cases have been reported since 2005. Males nearly comprise $57 \%$ of the cases [Table 2 ].

Governorates in Lebanon have different rates of HAV infection. Between January 2005 and December 2017, close to 63\% of all HAV cases were reported in the underserved Beqaa and North governorates. Individuals with HAV constituted $0.5 \%$ and $0.3 \%$ of the total populations of the Beqaa governorate $(750,000$ people) and North governorate (808,000 people), respectively. The governorate with the least reported HAV cases is the capital, Beirut, with only $2.5 \%$ of HAV cases; cases constitute $<0.01 \%$ of its total population (2.5 million) [Figure 2].

\section{DISCUSSION}

A sharp rise in the number of reported HAV cases was observed in Lebanon as early as 2013 concurrent with the Syrian crisis and influx of refugees. The majority of cases reported in 2013 and 2014 involved Syrian refugees and their relevant areas of encampment, in the poorer Bekaa and North governorates.

\begin{tabular}{|c|c|c|c|c|c|}
\hline Author(s) & Year & Subject numbers & Age groups & Male: female & Seroprevalence (anti-HAV IgM or IgG) \\
\hline \multirow[t]{3}{*}{ Shamma'a et al. } & 1982 & Adults: 485 & $>20$ years & $229: 256-57: 59$ & $97.7 \% \operatorname{lgG}$ \\
\hline & & Children: I7| & Days -12 years & & $79.5 \% \lg G$ \\
\hline & & Foreigners: I I6 & $20-62$ years & & $38.8 \% \lg G$ \\
\hline Kalaajieh et al. & 2000 & 740 & $0.5-15$ years & I.8:I & $29.3 \% \lg G$ \\
\hline \multirow[t]{3}{*}{ Sacy et al. } & 2005 & 606 & $\mathrm{I}-5$ years & $91: 111$ & $11 \% \lg G$ \\
\hline & & & $6-10$ years & & $28 \% \lg G$ \\
\hline & & & $21-30$ years & & $78 \% \lg G$ \\
\hline Bizri et al & 2006 & 902 & $14-18$ years & $339: 563$ & $62.8 \% \lg G$ \\
\hline \multirow[t]{4}{*}{ Melhem et al } & 2015 & 283 & $19-29$ years & $221: 62$ & $60 \% \lg G$ \\
\hline & & & $30-39$ years & & $77 \% \lg G$ \\
\hline & & & $40-49$ years & & $94 \% \lg G$ \\
\hline & & & $50-59$ years & & $91 \% \lg G$ \\
\hline
\end{tabular}

\begin{tabular}{|c|c|c|c|c|c|c|c|c|c|c|c|}
\hline Year & $0-4$ years & 5-9 years & $10-19$ years & $20-39$ years & $40-59$ years & $60+$ years & Unknown age & Male & Female & Unknown sex & Total \\
\hline 2005 & 33 & 54 & 62 & 31 & 3 & 5 & 22 & 125 & 83 & 2 & 210 \\
\hline 2006 & 24 & 83 & 115 & 60 & 7 & 2 & 17 & 162 & 145 & 1 & 308 \\
\hline 2007 & 65 & $|5|$ & 209 & 98 & 8 & 3 & 24 & 325 & 233 & 0 & 558 \\
\hline 2008 & 85 & 190 & 219 & 120 & 9 & 2 & 23 & 379 & 269 & 0 & 648 \\
\hline 2009 & 66 & 156 & 293 & 168 & 13 & 3 & 57 & 451 & 304 & 1 & 756 \\
\hline 2010 & 33 & 85 & 101 & 88 & 8 & 3 & 5 & 199 & 123 & 1 & 323 \\
\hline 2011 & 48 & 130 & 172 & 83 & 7 & I & 7 & 256 & 192 & 0 & 448 \\
\hline 2012 & 125 & 188 & 266 & 144 & 17 & 4 & 13 & 440 & 316 & I & 757 \\
\hline 2013 & 161 & 360 & 592 & 357 & 35 & 6 & 40 & 862 & 686 & 3 & $|55|$ \\
\hline 2014 & 291 & 652 & 959 & 485 & 30 & 9 & 147 & 1383 & 1185 & 5 & 2573 \\
\hline 2015 & 111 & 197 & $34 I$ & 254 & 23 & 8 & 51 & 589 & 396 & 0 & 985 \\
\hline 2016 & 70 & 93 & 200 & 123 & 9 & 2 & 22 & 307 & 212 & 0 & 519 \\
\hline 2017 & 136 & 153 & 207 & 230 & 28 & 5 & 17 & 450 & 326 & 0 & 776 \\
\hline Overall & 1248 & 2492 & 3736 & 2241 & 197 & 53 & 445 & 5928 & 4470 & 14 & 10,412 \\
\hline
\end{tabular}




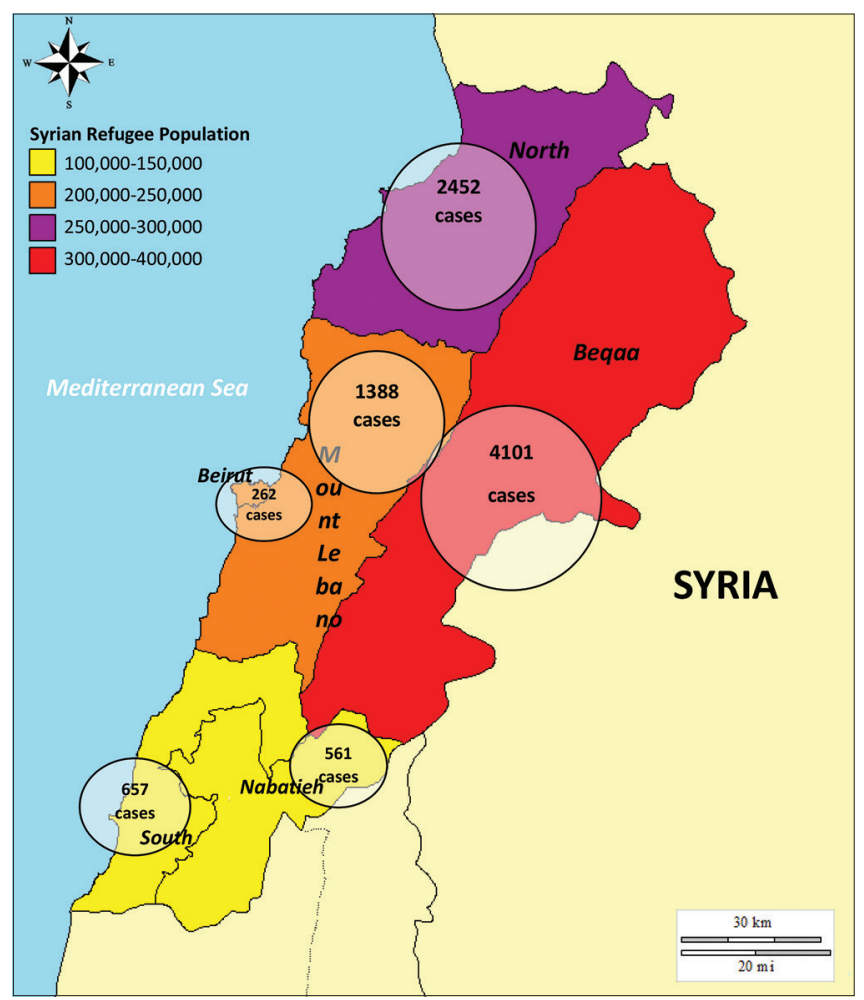

Figure 2: A map of Lebanon showing the distribution of the Syrian refugee population in the different governorates as per the United Nations High Commissioner for Refugees records in 2017, and the number of hepatitis A virus cases reported in every governorate (2005-2017, inclusive): Areas along the Syrian-Lebanese border (Beqaa and North) have the highest number of Syrian refugees and hepatitis $A$ virus cases reported

Before the Syrian conflict, the Beqaa and North governorates were underserved in terms of investment and infrastructure. The entry of large numbers of refugees increased the strain on the available infrastructure and public health services. The substandard water management system, along with the absence of developmental projects in some of the Lebanese governorates, like Beqaa and North, facilitated the spread of the disease. Studies have shown that groundwater and surface water in Lebanon are at risk of carrying HAV due to largely untreated sewages in many Lebanese areas. ${ }^{[20]}$

The Syrian civil war has caused more than 6.5 million Syrians to be displaced internally and 5.6 million to be spread as refugees around the world. ${ }^{[17]}$ Lebanon is host to 1 million registered refugees in Syria with the majority residing in the Beqaa and North governorates; ${ }^{[17]}$ it is estimated that there are around 137,000 refugees living in at least 990 informal tented settlements across the country. ${ }^{[21]}$ In addition, many of the refugees are not registered with UNHCR and/or are unreachable, further exacerbating their situation, particularly in regards to health-care access. ${ }^{[21]}$

Most refugees in informal tented settlements lack access to bottled water or water supply networks, as these sources can be expensive. In addition, the informal nature of the settlements makes providing sanitary infrastructure particularly challenging. ${ }^{[21]}$ Accumulation of solid waste and lack of access to sewage networks leads to open defecation in many settlements. ${ }^{[21,22]}$ Poor water quality, combined with overcrowding and unsanitary conditions, significantly worsens the problem. It is estimated that improving water resources in refugee camps will cost $95 \mathrm{USD} /$ beneficiary. ${ }^{[21]}$ The Lebanese Ministry of Energy and Water estimates the need for 280 million USD/year, to serve the country's 4 million inhabitants, that are already facing a $40 \%$ water supply deficit, and the extra 1.2 million displaced Syrians dispersed over Lebanese territories. ${ }^{[22]}$

Lebanon communicated the problem to the $67^{\text {th }}$ World Health Assembly where a new resolution for HAV was set that includes plans to improve actions related to health promotion and prevention of viral hepatitis, encouraging and reinforcing immunization strategies. ${ }^{[23]}$ Moreover, Lebanon received help from many international organizations including the United Nations Children's Fund and United States Agency for International Development to improve and guarantee the access of citizens to inexpensive, safe, and reliable water. ${ }^{[24]}$ Subsequently, in 2016, the number of reported HAV cases dropped to 519, around half the number of cases in 2015, showing early signs of better control of the situation.

Vaccination can provide active acquired immunity to HAV. As the health-care system in Lebanon is largely predominated by the private sector, ${ }^{[25]} \mathrm{HAV}$ vaccine is currently offered at a cost through pediatricians, family physicians, and infectious diseases specialists. The Lebanese MOPH continues to prioritize hygiene awareness campaigns over vaccinations in their fight against HAV. Currently, HAV vaccination is not one of the required vaccines supplied by the public sector and through the primary health-care network, which immunizes $60 \%-80 \%$ of nationals and most Syrian refugees. ${ }^{[26]}$ Barriers that stand in the way of nationalizing the HAV vaccine are mainly financial. Implementing funds to secure HAV vaccination would require delaying the introduction of other essential pediatric vaccines such as conjugated pneumococcal vaccine-13 and Rotavirus vaccine.

Prevention of HAV in Lebanon can be achieved by several interventions including providing adequate and safe water supply, vamping the living conditions of nationals and refugees in underserved areas, and universal immunization of children. More than 20 countries - 4 from the Middle East, including Bahrain, Saudi Arabia, United Arab Emirates, and Qatar - have integrated HAV vaccination in 
their national immunization programs. ${ }^{[27]}$ Studies from the United States, ${ }^{[28]}$ Argentina, ${ }^{[29]}$ and China ${ }^{[30]}$ have shown a reduction reaching $90 \%$ in acute HAV incidence a few years after initiation of mass vaccination. We believe that free HAV vaccination to vulnerable populations will reduce the illness burden, including hospital admissions.

\section{CONCLUSION}

The changing epidemiology of HAV has rendered more Lebanese adolescents and adults susceptible to overt clinical disease. This enhanced susceptibility to symptomatic illness can lead to major economic consequences. Lebanon has carried a major burden of the Syrian refugee crisis with a significant number of individuals residing in the country. Several factors combined together coupled with severe conditions related to war, crisis, overcrowding, suboptimal sanitary infrastructure, and overstretched public health and medical assets might have led to the increase in the incidence of reportable HAV infections in the country. Pending reaching a permanent resolution to the Syrian crisis, the Lebanese health authorities and the international community need to intensify their efforts in surveillance and prevention of communicable diseases. Accessibility and sustainability of safe water supplies, adequate sanitary infrastructure, and immunization if economically feasible, are the most important interventions to contain and prevent the spread of HAV and other similarly transmissible infectious diseases. The Lebanese scenario can be eye-opening to other countries that host Syrian refugees in the region where resources are limited and the risk of spread of communicable diseases is high. The situation in industrialized countries that have already welcomed Syrian refugees could be more complex since herd immunity is less prevalent among the host community.

\section{Financial support and sponsorship}

Nil.

\section{Conflicts of interest}

There are no conflicts of interest.

\section{REFERENCES}

1. Alawieh A, Musharrafieh U, Jaber A, Berry A, Ghosn N, Bizri AR, et al. Revisiting leishmaniasis in the time of war: The Syrian conflict and the Lebanese outbreak. Int J Infect Dis 2014;29:115-9.

2. Bell BP, Wasley A, Shapiro CN, Margolis HS. Prevention of hepatitis A through active or passive immunization: Recommendations of the advisory committee on immunization practices [ACIP]. MMWR 1999;48:i-37.

3. World Health Organization. Hepatitis A Factsheet; 5 July, 2017. Available from: http://www.who.int/news-room/fact-sheets/detail/ hepatitis-a. [Last accessed on 2018 Jul 25].
4. Yayli G, Kiliç S, Ormeci AR. Hepatitis agents with enteric transmission - an epidemiological analysis. Infection 2002;30:334-7.

5. Ghorbani GA, Mahboobi N, Lankarani KB, Alavian SM. Hepatitis a prevention strategies, Haiti case: Should rescuers be immunized. Iran Red Crescent Med J 2010;12:221.

6. Alavi Moghaddam M. Hepatitis A virus: A major global public health problem, especially in developing countries. Hepat Mon 2005;5:145-9.

7. Al Rashed RS. Prevalence of hepatitis A virus among Saudi Arabian children: A community-based study. Ann Saudi Med 1997;17:200-3.

8. Khalil M, Al-Mazrou Y, Al-Jeffri M, Al-Howasi M. Childhood epidemiology of hepatitis A virus in Riyadh, Saudi Arabia. Ann Saudi Med 1998;18:18-21.

9. Tufenkeji H. Hepatitis A shifting epidemiology in the Middle East and Africa. Vaccine 2000;18 Suppl 1:S65-7.

10. Jacobsen KH, Koopman JS. Declining hepatitis A seroprevalence: A global review and analysis. Epidemiol Infect 2004;132:1005-22.

11. Melhem NM, Talhouk R, Rachidi H, Ramia S. Hepatitis A virus in the Middle East and north Africa region: A new challenge. J Viral Hepat 2014;21:605-15.

12. Kalaajieh W, Rima A, Dennaoui M, Al Khodayry R. Seroprevalence of hepatitis A antibodies in Lebanese children. Med Mal Infect 2000;30:757-61.

13. Sacy RG, Haddad M, Baasiri G, Khoriati A, Gerbaka BJ, Abu-Elyazeed R, et al. Hepatitis a in Lebanon: A changing epidemiological pattern. Am J Trop Med Hyg 2005;73:453-6.

14. Bizri AR, Nuwayhid IA, Hamadeh GN, Steitieh SW, Choukair AM, Musharrafieh UM, et al. Association between hepatitis A virus and helicobacter pylori in a developing country: The saga continues. J Gastroenterol Hepatol 2006;21:1615-21.

15. Melhem NM, Jaffa M, Zaatari M, Awada H, Salibi NE, Ramia S, et al. The changing pattern of hepatitis A in Lebanese adults. Int J Infect Dis 2015;30:87-90.

16. Burki T. Infectious diseases in Malian and Syrian conflicts. Lancet Infect Dis 2013;13:296-7.

17. United Nations High Commission on Refugees. Syrian Regional Refugee Response; 19 July, 2018. Available from: https:/www.data2.unhcr.org/ en/situations/syria. [Last accessed on 2018 Jul 25].

18. Shamma'a MH, Abu-Samra S, Salameh V, Nassar NT. The significance of anti-HAV in different population sectors in Lebanon: A comparative seroepidemiologic study. Int J Epidemiol 1982;11:406-9.

19. Republic of Lebanon Ministry of Public Health. Epidemiological Surveillance: General Surveillance Data; 2018. Available from: http:// www.moph.gov.lb/en/Pages/2/193/epidemiological-surveillance. [Last accessed on $2018 \mathrm{Jul} 25]$.

20. Assaf H, Saadeh M. Geostatistical assessment of groundwater nitrate contamination with reflection on DRASTIC vulnerability assessment: The case of the Upper Litani Basin, Lebanon. Water Resour Manag 2009;23:775-96.

21. UNICEF. UNICEF Lebanon: Immunization; 20 May, 2014. Available from: https:/www.unicef.org/lebanon/thematic_factsheets.pdf. [Last accessed on 2018 Jul 25].

22. United Nations Development Programme. Lebanon Crisis Response Plan (LCRP) 2017-2020; 16 July, 2017. Available from: https://www. reliefweb.int/sites/reliefweb.int/files/resources/2017_2020_LCRP_ ENG-1.pdf. [Last accessed on 2018 Jul 25].

23. World Health Organization. World Health Assembly Approves Resolution on Hepatitis and Mechanism to Coordinate Noncommunicable Disease Response; 22 May, 2014. Available from: http://www.who.int/ mediacentre/news/releases/2014/WHA-20140522/en/. [Last accessed on 2018 Jul 25].

24. United States Agency for International Development. USAID Water and Development Strategy 2013-2018; 15 May, 2013. Available from: https:/www.usaid.gov/sites/default/files/documents/1865/USAID_ Water_Strategy_3.pdf. [Last accessed on 2018 Jul 25]. 
25. Fares Y, Fares J. Neurosurgery in Lebanon: History, development, and future challenges. World Neurosurg 2017;99:524-32.

26. UNICEF. UNICEF in Lebanon and immunization campaigns. Hum Health 2017;38:12-5.

27. World Health Organization. World Health Organization Vaccine-Preventable Diseases: Monitoring System 2018 Global Summary; 15 July, 2018. Available from: http://www.apps.who.int/immunization monitoring/globalsummary. [Last accessed on 2018 Jul 25].

28. Bialek SR, Thoroughman DA, Hu D, Simard EP, Chattin J, Cheek J, et al. Hepatitis A incidence and hepatitis a vaccination among American Indians and Alaska Natives, 1990-2001. Am J Public Health 2004;94:996-1001.

29. Blanco Fernández MD, Torres C, Riviello-López G, Poma HR, Rajal VB, Nates S, et al. Analysis of the circulation of hepatitis A virus in Argentina since vaccine introduction. Clin Microbiol Infect 2012;18:E548-51.

30. Cui F, Hadler SC, Zheng H, Wang F, Zhenhua W, Yuansheng H, et al. Hepatitis A surveillance and vaccine use in China from 1990 through 2007. J Epidemiol 2009;19:189-95. 